\title{
Using energy substances as a way to enhance oil recovery
}

\author{
B. S. Moldabekov ${ }^{1}$, R. G. Sarmurzina ${ }^{3}$, G. I. Boyko ${ }^{1}$, \\ U. S. Karabalin ${ }^{4}$, G. G. Kurapov ${ }^{1} \&$ N. P. Lubchenco ${ }^{2}$ \\ ${ }^{1}$ Kazakh National Technical University named after K. I. Satpayev, \\ Kazakhstan \\ ${ }^{2}$ Unat University, Kazakhstan \\ ${ }^{3}$ National company KazMunayGaz, Kazakhstan \\ ${ }^{4}$ KazEnergy, Kazakhstan
}

\begin{abstract}
The productivity of oil wells is determined by the hydrocarbon reserves of deposits, and the qualitative condition of the bottomhole formation zone and its permeability. Known various intensification technologies of well productivity are: thermal, gas and physicochemical methods. The authors of this research developed and tested energy accumulating substances based on aluminum Rau-85, at the same time combining both physical and chemical methods of layer stimulation. Developed alloys and composites have significant advantages over known compositions. Under laboratory conditions, experiments were carried out to test the influence of aluminum alloys on the composition and properties of reservoir fluids (oil, water) Kumkol's field. The studies were conducted at atmospheric pressure and at a process temperature of $20^{\circ} \mathrm{C}$. Experimentally, it was shown that the oxidation of the Rau- 85 by water-oil emulsion at the temperature of $20^{\circ} \mathrm{C}$ is characterized by an inductive period (3-4 minutes) with a further self-heating of up to $65^{\circ} \mathrm{C}$ and releasing of heat and gases. Collected gases were analyzed by a chromatograph GC-1000 Chromos. The gas composition contains a considerable amount of hydrogen, methane, butane, oxygen and $\mathrm{CO}_{2}$. The content of other gases is negligible. Analysis of the physicochemical properties of the oil obtained after processing by Rau- 85 shows that in comparison with the untreated oil density they increased from 0.809 to $0.812 \mathrm{~g} / \mathrm{cm}^{3}$, and the kinematic viscosity decreased from 9.66 to $7.99 \mathrm{~mm}^{2} / \mathrm{s}$. Yield of light fractions of up to $180^{\circ} \mathrm{C}$ increased by $4 \%$. Fractions were analyzed according to ASTM D 5292-99 NMR spectrometer BrukerAVANC 3-400. It is shown that the content of aromatic hydrocarbons in the fraction of up to $120^{\circ} \mathrm{C}$ increased, and the fraction above $180^{\circ} \mathrm{C}$ decreased. The
\end{abstract}


presence of gases such as oxygen, $\mathrm{CO}_{2}$, methane and other low-molecular hydrocarbons indicates the process of cracking and oxidation. It is known that one of the areas of enhanced oil recovery is where injected gases and heating oil are found in the reservoir. According to this, the use of reactant Rau- 85 will lead to enhanced oil recovery.

Keywords: enhanced oil recovery, thermo chemical well treatment, energy accumulating substances.

\section{Introduction}

Productivity of oil wells is determined by hydrocarbon reserves of deposits, qualitative condition of the bottomhole formation zone and its permeability. Currently, most of the world's largest producing fields are located on the later stages of production, and their remaining reserves are classified as difficult to produce. When the field is characterized by a high degree of water content and depletion to improve the effectiveness of production used enhanced oil recovery (EOR) methods, as thermal, gas and physicochemical. According to some companies increasing the recovery factor by $1 \%$ globally will increase the conventional oil reserves up to 88 billion barrels, which is almost three times higher than the current level of annual production [1-2].

The authors of this paper developed and tested energy accumulating substances based on aluminium Rau-85, combining both physical and chemical methods formation stimulation.

\section{The main study}

The influence of aluminum alloys on the composition and properties of Kumkol field reservoir fluids (oil, water) was simulated under laboratory conditions. Oil treatment by aluminum composition was done at atmospheric pressure in a sealed vessel under inert gas atmosphere. During treatment, the rapid evolution of gases and heat is observed. Oil-water mixture is heated to a temperature of $65^{\circ} \mathrm{C}$ and the temperature on the surface with Rau- 85 reaches $600^{\circ} \mathrm{C}$. As it is well known, pumping gas and thermo heating positively affect enhanced oil recovery [1-2].

Gases were analyzed by chromatograph Chromos GC-1000. In this chromatograph determination of substances occurs in three columns. The first column identifies the gases $\mathrm{H}_{2}, \mathrm{O}_{2}$, argon and $\mathrm{N}_{2}$ with a thermal conductivity detector. The second column identifies $\mathrm{CH}_{4}, \mathrm{CO}_{2}$ and $\mathrm{CO}$ with flame-ionization detector (FID). On the third are determined hydrocarbon gases with FID. Gas carrier is argon. Chromatograms are shown in figures $1-3$. Observed high content of hydrogen $0.028 \mathrm{~g} / \mathrm{l}$, oxygen $0,103 \mathrm{~g} / \mathrm{l}$ and methane $0.036 \mathrm{~g} / \mathrm{l}$. Gas composition is shown in table 1 . The content of such gases as $\mathrm{CO}_{2}$, methane, ethane, propane and butane indicates to cracking process. According to the paper [3] hydrogen is an activator of diffusion processes in the cores of productive layers. In turn, known methods for increasing oil recovery by pumping air whereby the oil reacts with oxygen releasing heat. Consequently high contents of hydrogen and oxygen will increase oil recovery. 


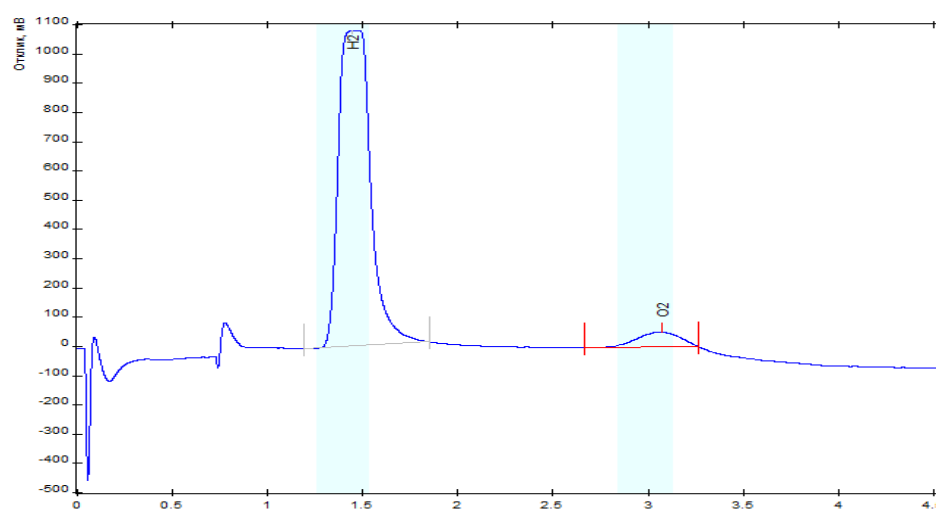

Figure 1: Chromatogram $\mathrm{H}_{2}$ и $\mathrm{O}_{2}$ gases.

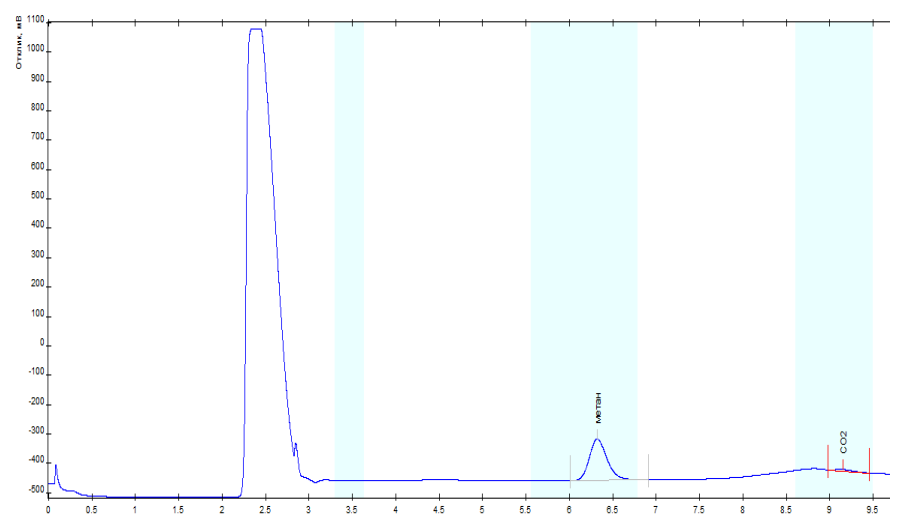

Figure 2: Chromatogram $\mathrm{CH}_{4}$ и $\mathrm{CO}_{2}$ gases.

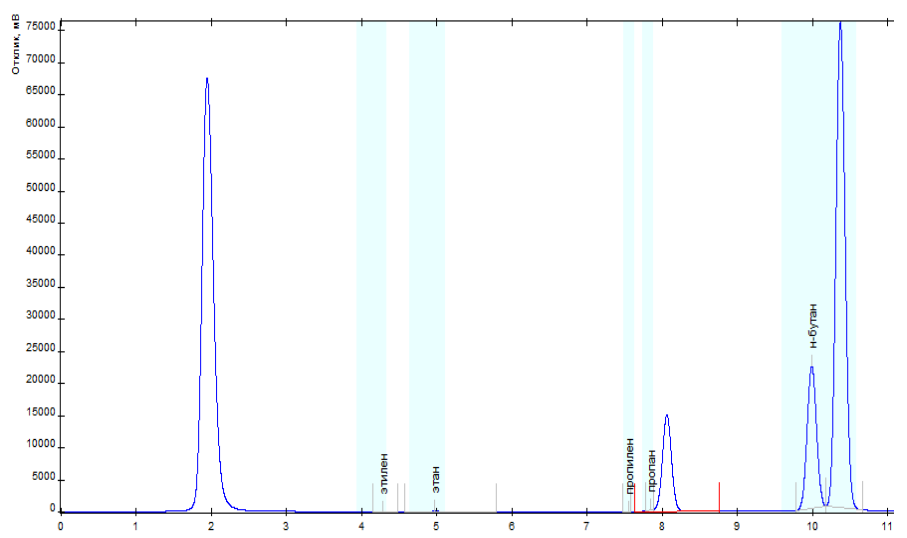

Figure 3: Chromatogram hydrocarbon gases. 
Table 1: Gas composition.

\begin{tabular}{|l|l|}
\hline Gas & Concentration, $\mathrm{g} / \mathrm{l}$ \\
\hline Hydrogen & 0.028 \\
\hline Oxygen & 0.103 \\
\hline $\mathrm{CO}_{2}$ & 0.0034 \\
\hline Methane & 0.036 \\
\hline Ethane & traces \\
\hline Propane & 0.001 \\
\hline n-butane & 0.0008 \\
\hline
\end{tabular}

\subsection{Investigation of physicochemical properties of oil}

Table 2 shows kinematic viscosity and density of the oil before and after treatment according with ASTM [4-5]. After treatment oil density increased and oil viscosity decreased. This may be due to increase in content of aromatic hydrocarbons having higher density and lower viscosity.

Table 2: Physicochemical properties of oil before and after treatment.

\begin{tabular}{|l|c|c|}
\hline Parameter & Before treatment & After treatment \\
\hline Density, $\mathrm{g} / \mathrm{cm}^{3}$ & 0.809 & 0.812 \\
\hline $\begin{array}{l}\text { Kinematic viscosity, } \mathrm{mm}^{2} / \mathrm{s} \\
\text { at } 25^{\circ} \mathrm{C}\end{array}$ & 9.66 & 7.964 \\
\hline
\end{tabular}

For quantitative fractional oil characteristics before and after treatment samples were distillated on fraction (Table 3). Following changes was observed. Output fraction boiling in the range of $60-80^{\circ} \mathrm{C}$ and $100-120^{\circ} \mathrm{C}$ increased by 1 and $2.4 \%$, respectively. As a result, the sum of fractions to $120^{\circ} \mathrm{C}$ increased by almost $3 \%$. Output of the fraction $140-160^{\circ} \mathrm{C}$ after treatment decreased by $1 \%$, and $160-180^{\circ} \mathrm{C}$ increased by $1.3 \%$. That indicates its composition change.

Table 3: Fractional distillation of the oil before and after treatment.

\begin{tabular}{|l|c|c|}
\hline \multirow{2}{*}{$\begin{array}{l}\text { Boiling fraction } \\
\text { range, }{ }^{\circ} \mathrm{C}\end{array}$} & \multicolumn{2}{|c|}{ Output, Vol\% } \\
\cline { 2 - 3 } & Before treatment & After treatment \\
\hline Up to 60 & 2.4 & 2.1 \\
\hline $60-80$ & 1.1 & 2.1 \\
\hline $80-100$ & 3 & 2.63 \\
\hline $100-120$ & 3.9 & 6.32 \\
\hline Up to 120 & 10.4 & 13.15 \\
\hline $120-140$ & 3.6 & 3.16 \\
\hline $140-160$ & 3 & 2.1 \\
\hline $160-180$ & 4.5 & 5.79 \\
\hline $120-180$ & 11.1 & 11.052 \\
\hline Up to 180 & 21.5 & 24.2 \\
\hline
\end{tabular}




\subsection{NMR spectra fractions before and after treatment}

NMR spectra were recorded on fractions multinuclear NMR Fourier spectrometer of high resolution UltraShield-400(Bruker), according to standard ASTM D 529299 [6].

The method involves $1 \mathrm{H}$ NMR spectrum of the investigated products. Then integrates two areas 0 to $5 \mathrm{ppm}$ (aliphatic hydrogen bonds) (A) and from 5 to 10 ppm (aromatic hydrogen bond) (B). The solvent was d-chloroform. Then, according to eqn. (1) hydrogen content was calculated in aromatics. NMR spectra are shown in figures 4-7, and integrating results in table 4. Spectra showed that the hydrogen content of aromatics in the fraction up to $120^{\circ} \mathrm{C}$ increased, and in fraction above 180 decreased. According to [3] cracking and pyrolysis affects firstly highly molecular hydrocarbons with long and branched chain carbon atoms. Changed hydrogen content could be as result hydrocracking of long and branched chain carbon atoms.

$$
\text { Hydrogen content in aromatic }=\frac{\mathrm{B}}{\mathrm{A}+\mathrm{B}}
$$

Table 4: Results of integration.

\begin{tabular}{|l|c|c|}
\hline \multirow{2}{*}{$\begin{array}{l}\text { Boiling fraction } \\
\text { range, }{ }^{\circ} \mathrm{C}\end{array}$} & \multicolumn{2}{|c|}{ Hydrogen content in aromatic, \% } \\
\cline { 2 - 3 } & Before treatment & After treatment \\
\hline up 120 & 1.1 & 1.57 \\
\hline $120-180$ & 0.76 & 0.16 \\
\hline$>180$ & 2.62 & 1.28 \\
\hline
\end{tabular}

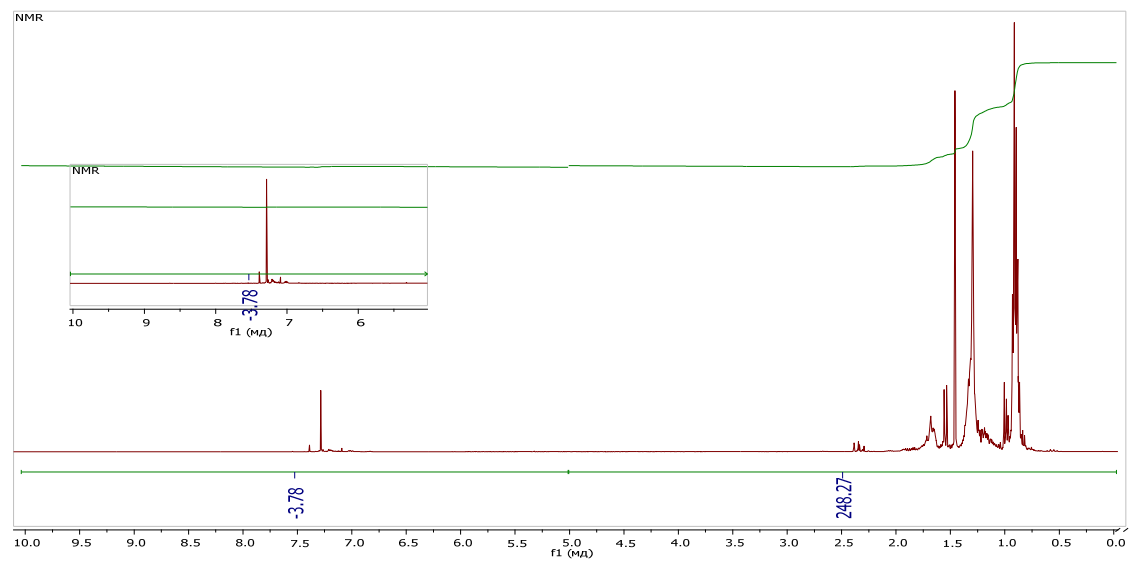

Figure 4: NMR spectrum fraction up to $120^{\circ} \mathrm{C}$ before treatment. 


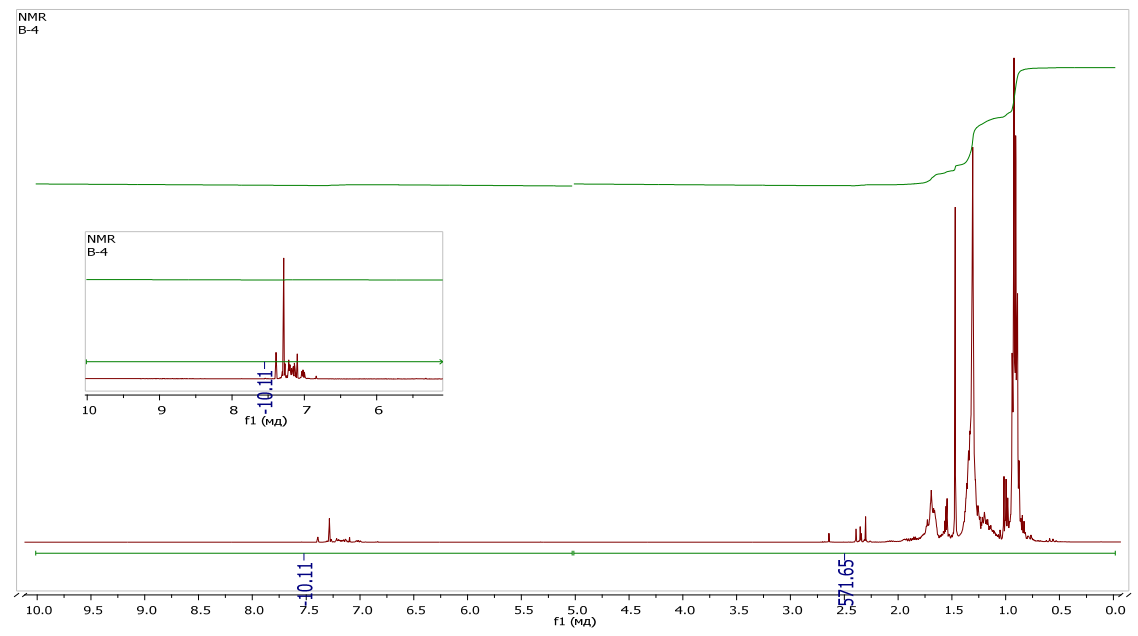

Figure 5: NMR spectrum fraction up to $120^{\circ} \mathrm{C}$ after treatment.

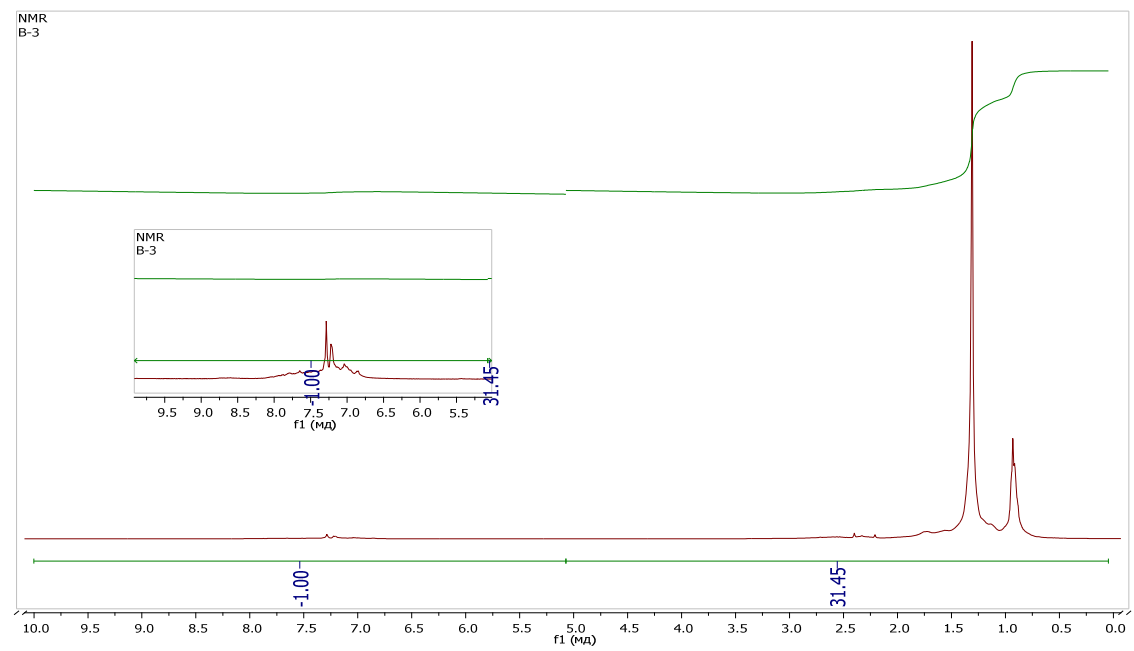

Figure 6: NMR spectrum of fraction $>180^{\circ} \mathrm{C}$ before treatment. 


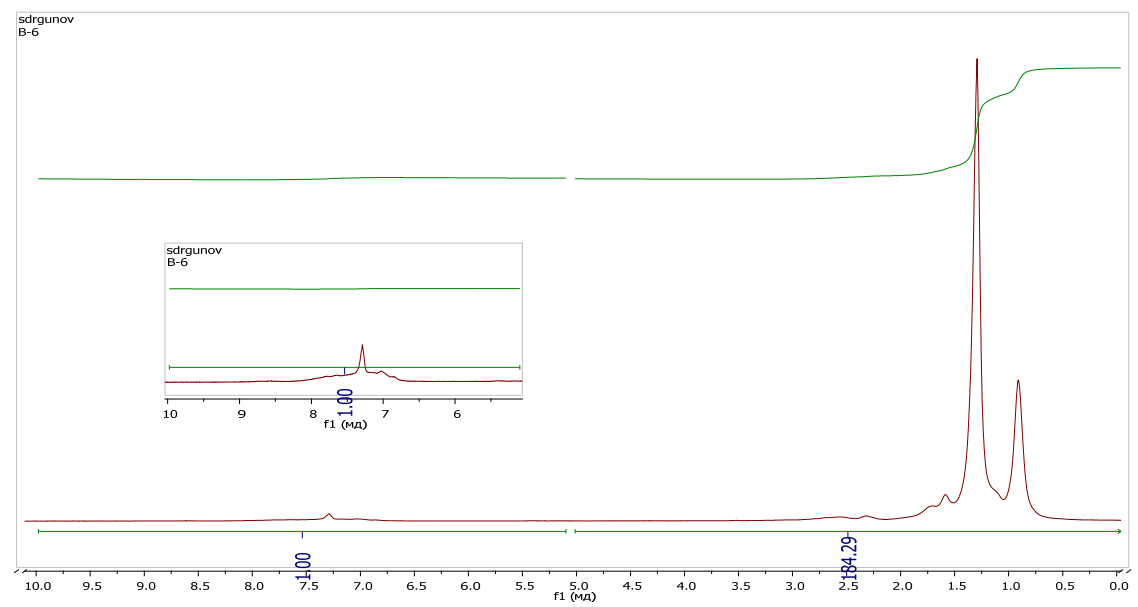

Figure 7: NMR spectrum of fraction $>180^{\circ} \mathrm{C}$ after treatment.

Under laboratory conditions, were carried out the influence of aluminum alloys on the composition and properties of reservoir fluids (oil, water) Kumkol's field. Releasing heat and gases, changing psychochemical properties, increasing aromatic content and gases such as hydrogen and oxygen, all these factors will lead to enhance oil recovery.

\section{References}

[1] Sheng, J.J., (eds). Enhanced Oil Recovery Field Case Studies, Elsevier: USA, 2013.

[2] Lake L.W., Enhanced Oil Recovery, Society of petroleum Engineers, pp. 2-12, 2010.

[3] Kravchenko O.V. Hydrogen activation to increase permeability of petroliferous rocks, Organic and inorganic substances technology, pp. 21-25, 2013. http://journals.uran.ua/eejet/article/viewFile/9189/7984

[4] ASTM D1217-93R03E01 Test Method for Density and Relative Density (Specific Gravity) of Liquids by Bingham Pycnometer, Annual Book of ASTM Standards, Vol. 05.01, ASTM International, West Conshohocken, PA.

[5] ASTM D0445-04E01 Test Method for Kinematic Viscosity of Transparent and Opaque Liquids (and the Calculation of Dynamic Viscosity), Annual Book of ASTM Standards, Vol. 05.01, ASTM International, West Conshohocken, PA.

[6] ASTM D5292-99R04 Test Method for Aromatic Carbon Contents of Hydrocarbon Oils by High Resolution Nuclear Magnetic Resonance Spectroscopy, Annual Book of ASTM Standards, Vol. 05.02, ASTM International, West Conshohocken, PA. 